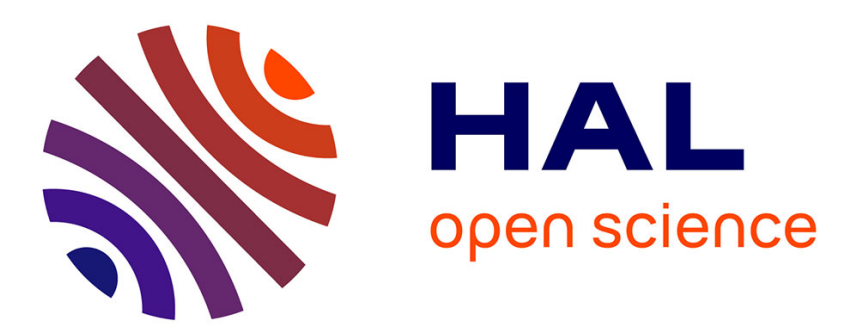

\title{
Identification of strain rate-dependent mechanical behaviour of DP600 under in-plane biaxial loadings
}

Wei Liu, Dominique Guines, Lionel Leotoing, Eric Ragneau

\section{To cite this version:}

Wei Liu, Dominique Guines, Lionel Leotoing, Eric Ragneau. Identification of strain rate-dependent mechanical behaviour of DP600 under in-plane biaxial loadings. Materials Science and Engineering: A, 2016, 676, pp.366 - 376. 10.1016/j.msea.2016.08.125 . hal-01394743

\section{HAL Id: hal-01394743 \\ https://hal.science/hal-01394743}

Submitted on 9 Nov 2016

HAL is a multi-disciplinary open access archive for the deposit and dissemination of scientific research documents, whether they are published or not. The documents may come from teaching and research institutions in France or abroad, or from public or private research centers.
L'archive ouverte pluridisciplinaire HAL, est destinée au dépôt et à la diffusion de documents scientifiques de niveau recherche, publiés ou non, émanant des établissements d'enseignement et de recherche français ou étrangers, des laboratoires publics ou privés. 


\title{
Identification of strain rate-dependent mechanical behaviour of DP600 under in-plane biaxial loadings
}

\author{
Wei LIU ${ }^{(1)}$, Dominique GUINES ${ }^{(2)}$, Lionel LEOTOING ${ }^{(2)}$, Eric RAGNEAU ${ }^{(2)}$ \\ Corresponding author : Dominique GUINES, dominique.guines@insa-rennes.fr \\ ${ }^{(1)}$ School of Materials Science and Engineering, Wuhan University of Technology (WHUT), China \\ ${ }^{(2)}$ Université Européenne de Bretagne, INSA-LGCGM-EA 3913, 20 Av. des Buttes de Coësmes, CS \\ 70839, 35708 Rennes Cedex 7, France
}

\begin{abstract}
The rate-dependent hardening behaviour of dual phase DP600 steel sheet is investigated by means of in-plane biaxial tensile tests, in an intermediate strain rate range (up to $20 \mathrm{~s}^{-1}$ ) and for large strains (up to $30 \%$ of equivalent plastic strain) at room temperature. The dynamic biaxial inplane tensile tests are performed on a dedicated cruciform specimen shape previously developed and validated for large strains at quasi-static conditions. To perform dynamic biaxial tensile tests, a specific device is used to reduce oscillations on measure of forces. Based on these experiments, parameters of two phenomenological strain-rate hardening models (saturated and power law), are identified. Material parameters are obtained from an optimization process, based on the finite element modelling of the biaxial test, by minimizing differences between experimental and simulated principal strains at the specimen centre. A comparison of the strain hardening functions calibrated from both biaxial and uniaxial tensile tests under static and dynamic conditions are then proposed. Results show that the biaxial procedure developed in this work, associated with a specific shape of the cross specimen, are more efficient to determine the rate-dependent hardening behaviour for large strains than the conventional uniaxial tensile test.
\end{abstract}

Keywords: Biaxial test, Cruciform specimen, Hardening model, Rate-dependent behaviour, Metallic sheet, DP600.

\section{Introduction}

In many industrial fields (automotive, aeronautical, shipbuilding, railway, ...), sheet metal forming processes are widely adopted to produce more and more complex parts. The lightening, the enhancement of safe design, the cost decrease of both the design stage and the manufacturing process 


\section{ACCEPTED MANUSCRIPT}

are challenging issues in these industries. These objectives lead to the increasing adoption of the simulation tool, usually based on Finite Element (FE) numerical simulations. For material behaviour modelling, accurate constitutive models are then required and have to be implemented in FE codes. Today, phenomenological approach remains predominant to model material behaviours. These models have to be characterized and calibrated by means of experimental techniques carefully designed to carry out tests at conditions met both in the considered sheet metal forming processes and in service. Depending on the forming operation and service conditions, multi-axial loadings, large plastic strains, thermal and rate-dependencies of the material usually have to be investigated. The most popular experimental test used to characterize sheet metal behaviour is the uniaxial tensile test. Nevertheless, only uniaxial stress and strain states and relatively low strain levels, compared to the ones obtained in forming operations, can be reached. In order to obtain information concerning multiaxial loading conditions encountered in sheet forming processes, several tests have been developed such as, tension tests on wide specimens [1,2], combined plane strain-simple shear test on only one specimen [3,4], hydraulic bulge tests with circular or elliptical die openings [5], combined uniaxial tension-internal pressure tests [6], Marciniak [7] or Nakazima stamping tests [8] and biaxial tensile tests on flat cruciform specimen $[9,10]$. As shown in these last works, the biaxial tensile test on a flat cruciform specimen presents several advantages: it is a frictionless test, it allows to reach large plastic strains and linear and non-linear strain paths can be easily achieved. Nevertheless, strain-rate dependency of metallic sheets has not yet been studied with such experimental device.

Various dynamic tests have been performed to identify strain rate dependent hardening law in the intermediate strain rate range. For dynamic tests, depending on the initial impact velocity at the beginning of the test, an oscillation phenomenon of the force signal measured by the load cell, called as loading ringing [11], can be observed. Those variations of the experimental force can be induced by the propagation of an elastic stress or strain wave or by the vibratory response of mechanical parts of the experimental device [12]. Huh et al. [13] have developed a high speed uniaxial testing machine to investigate dynamic tensile behaviour of steel sheets in the strain rate range from $0.003 s^{-1}$ up to $200 s^{-1}$. The grip attached to the load cell has been shorted to increase the natural frequency. This designed grip has been validated to reduce the load ringing. For testing materials in the intermediate strain rate range from $10 s^{-1}$ up to $200 s^{-1}$, Gilat et al. [14] have introduced a new compression apparatus consisting in a large hydraulic actuator and a long transmitter bar of $40 \mathrm{~m}$ length. The experiment is completed before the reflected wave in the transmitter bar returns back to the strain gauge so that the measured force is not disturbed. Othman et al. [15] have developed a 


\section{ACCEPTED MANUSCRIPT}

modified servo-hydraulic machine to assess the mechanical properties of aluminium alloy 2017-T4 at the strain rate of approximately $10^{2} \mathrm{~s}^{-1}$. A long duration Hopkinson bar technique and a wave separation method are adopted for less oscillating force measurement. Wood et al. [16] have developed uniaxial tensile tests at the strain rates from quasi-static to $500 \mathrm{~s}^{-1}$. The force measured by the local force transducer on the specimen is less oscillating than the one measured by the dynamic load cell located between the grip and the machine frame. Diot et al. [17] have carried out uniaxial compressive tests to identify the constitutive model of a steel up to large strains of $150 \%$ and at the intermediate strain rate of $500 \mathrm{~s}^{-1}$. The force on the bar/specimen interface is firstly determined by inverse analysis based on the elastic FE model of tools. The plastic hardening model of material is then identified by applying the preliminarily identified force to the testing specimen. Fitoussi et al. [18] have conducted high speed uniaxial tensile tests on fibre reinforced polymer composites by a servo-hydraulic machine. A damping joint of a low impedance material is placed between the sliding bar and the hydraulic jack to reduce the wave effects caused by the dynamic shock. Boyce et al. [19] have performed uniaxial tensile tests on ultrahigh strength steels at the strain rates from $0.0002 s^{-1}$ to $200 s^{-1}$. A rubber damper placed in the slack adapter is validated to reduce the initial oscillations by more than 50\%. Xiao [20] has also adopted a damping layer to reduce load ringing for dynamic uniaxial tensile tests on plastic materials. As one can see, many works were interested in strain rate dependency of metallic alloy behaviour under uniaxial stress state.

Concerning stain rate sensitivity under biaxial loadings, very few studies have been published. Recently, Grolleau et al. [21] have proposed a dynamic bulge testing device to investigate the material behaviour under biaxial loadings conditions at intermediate strain rates. The hardening law of aluminium alloy A1611-T4 sheet at high strain rate of up to $500 \mathrm{~s}^{-1}$ is identified. A movable bulge cell is designed and installed in a split Hopkinson pressure bar (SHPB) system. Ramezani et al. [22] have also introduced a similar high strain rate bulge test technique on the basis of SHPB system. The analytical and finite element methods are compared with experiments to verify the developed method. In order to investigate the material behaviour under dynamic and different biaxial stress states, Shimamoto et al. [23] have developed a servo-hydraulic dynamic biaxial loading device. The inplane dynamic biaxial test on cruciform specimen is carried out to reveal the crack extension behaviour of aluminium alloy AA7075-T6 at 1m/s. Nevertheless, no calibration model is proposed in this work. Recently, a specific dynamic biaxial tensile device with four independent servo-hydraulic actuators (each one with a loading capacity of $50 \mathrm{kN}$ ) has been developed in the Laboratory of Civil and Mechanical Engineering (LGCGM) of National Institute of Applied Sciences (INSA) at Rennes 


\section{ACCEPTED MANUSCRIPT}

[24]. This biaxial tensile machine has been used to lead in-plane biaxial tensile tests on cruciform specimens at quasi-static strain rate for different applications: (i) calibration of yield criteria [25], (ii) identification of hardening laws at large strains [10] and (iii) determination of forming limit curves [9] of metallic sheets. Depending on applications, several in-plane specimen shapes have been proposed and validated and linear or non-linear strain paths can be imposed. Based on an instantaneous release of a great quantity of high pressure flow accumulated, this machine is also dedicated to perform dynamic tensile tests (a maximum velocity of $2 \mathrm{~m} / \mathrm{s}$ can be reached on each actuator) on flat cross specimens.

In the last few years, optical measurement techniques and image correlation techniques have been intensively used to calibrate material models. In most analyses reported in the literature, the identification is performed by minimizing a least-square functional based on the difference between experimental and numerical fields or discrete values of strains or displacement. Within the framework of quasi-static characterization, Meuwissen [26] designed sheet specimens of nonstandard geometry and optically measured the displacement of markers placed on the surface specimen. Belhabib [27] identify material parameters by fitting simulated and optical heterogeneous strain fields obtained from tensile tests on elastoplastic metallic sheet. On flat cruciform specimen, Zhang [25] used discrete values of principal strains along a diagonal direction of the central zone of a cruciform specimen. With a more complex cross specimen shape, Liu [10] used local strain measures in the specimen centre to identify hardening law of a 5086 aluminium alloy up to large strains. Due to the increasing acquisition frame rate of cameras, these non-contact techniques are now well adapted to dynamic characterizations and may be used for homogeneous or non-homogeneous tests. Kajberg [28] used specimens with non-uniform widths tested in tension. The state of deformation is quantified by an optical method, digital speckle photography (DSP), providing field information for both in-plane displacements and strains. The strain fields were then analysed for the numerical identification of the stress-strain relationship up to large strains.

In the present work, a dual phase advanced high strength steel (DP600), which combines high strength and good formability, is considered. It has been shown in previous works [29] that such steel grades exhibited rate-dependent behaviour. This strain rate dependency is first evaluated experimentally from uniaxial tensile tests at room temperature in a moderate strain rate range (from quasi-static conditions up to $20 \mathrm{~s}^{-1}$ ). Based on these observations, two phenomenological ratedependent hardening models are selected and calibrated. Then, static and dynamic equi-biaxial tests are performed on a dedicated cross specimen shape, previously developed and validated for quasi- 


\section{ACCEPTED MANUSCRIPT}

static applications [10], up to an equivalent plastic strain of $30 \%$. Parameters of the two ratedependent hardening formulations are identified from biaxial experiments by means of an optimization procedure minimizing the difference between local simulated and experimental strains in the specimen centre. The identified biaxial flow stress curves are then compared with uniaxial ones for the quasi-static and intermediate strain rates to show the benefits of the proposed methodology.

\section{Uniaxial tensile tests}

Initially, uniaxial characterizations of DP600 thin plate specimens are performed to establish the strain rate dependency of the elastoplastic behaviour of such alloys in an intermediate strain rate range. Based on these experimental observations, two phenomenological strain rate-dependent constitutive relationships are selected and calibrated up to the maximum strain level reached in uniaxial tension.

\subsection{Uniaxial flow stress curves}

Uniaxial tensile tests on DP600 were performed by dynamic servo-hydraulic testing machine at room temperature. The specimens have a constant cross section (width $\times$ thickness: $10 \mathrm{~mm} \times 2 \mathrm{~mm}$ ) over an initial gauge length of $50 \mathrm{~mm}$. For all specimens, the tensile direction corresponds to the rolling one. The loading speeds, $1 \mathrm{~mm} / \mathrm{s}, 100 \mathrm{~mm} / \mathrm{s}, 500 \mathrm{~mm} / \mathrm{s}$ and $1 \mathrm{~m} / \mathrm{s}$ correspond to initial true strain rates of $0.02 s^{-1}, 2 s^{-1}, 10 s^{-1}$ and $20 s^{-1}$, respectively. The oscillations on the measured force curves for dynamic tests are very small. Therefore, the measured force curves are post-processed by median filtering method to obtain smooth ones. A high speed camera (FASTCAM-APX RS) is used to film the specimen deformation and digital image correlation (DIC) technique is used to determine the true strain field at the specimen surface. An image resolution of $704 \times 128$ pixels and an acquisition rate from 250f/s to $15000 \mathrm{f} / \mathrm{s}$, respectively for the loading velocities $1 \mathrm{~mm} / \mathrm{s}$ and $1 \mathrm{~m} / \mathrm{s}$, are adopted. The commercial software CORRELA2006, developed by LMS at the University of Poitiers, is employed to carry out correlation analysis. Since the gauge area has a constant cross section, these tests can be considered homogeneous, at least over a restricted area, and an average value of strains at the surface of the specimen was calculated over this area. Stresses have been directly calculated from measures of force. Three tests are performed for each loading speed to ensure repeatability. The equivalent stress versus equivalent plastic strain curves up to the onset of diffuse necking are presented in Fig. 1. These curves will be used for parameter identification of hardening laws. The 


\section{ACCEPTED MANUSCRIPT}

initial yield points for the four different strain rates are determined by the conventional limit at $0.2 \%$ of strain.

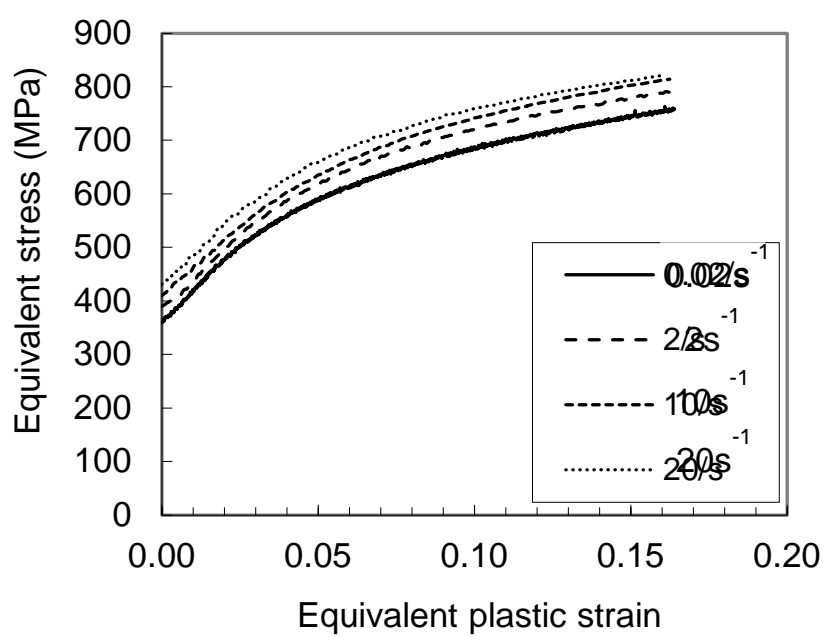

Fig. 1 Equivalent stress-plastic strain curves of DP600 by uniaxial tensile tests

It can be seen that DP600 exhibits a positive strain rate sensitivity in the tested strain rate range at room temperature. The maximum stress values at $0.02 s^{-1}$ and $20 s^{-1}$ are respectively $760 \mathrm{MPa}$ and $820 \mathrm{MPa}$, corresponding to an increase of about $8 \%$. In the observed strain range, the strain rate dependency seems to affect both the initial yield stress and the strain hardening. These trends (moderate rate sensitivity) have been already observed in previous works on the same material $[29,30]$.

\subsection{Strain rate dependent hardening law}

Many integrated constitutive equations relating equivalent flow stress $\bar{\sigma}$ with equivalent plastic strain $\overline{\varepsilon_{p}}$, equivalent total strain rate $\dot{\bar{\varepsilon}}$ and temperature $T$ have been proposed to describe the mechanical behaviour of metallic alloys. In the current work, the temperature is not considered so the different formulations used to describe the influence of this parameter on the flow stress are not discussed. Concerning the strain hardening function $H\left(\bar{\varepsilon}_{p}\right)$, two main types of formulations are usually encountered. The first one includes "saturation" models which present a saturation stress at large strains while the second one concerns "power-law" models which are unbounded at large strain. A typical formulation of these models is given by Ludwick's (Eq. 1) and Voce's (Eq. 2.) equations which present respectively the saturated and unsaturated behaviour:

$$
\bar{\sigma}=\sigma_{0}+H\left(\bar{\varepsilon}_{p}\right)=\sigma_{0}+K \bar{\varepsilon}_{p}^{n}
$$




$$
\bar{\sigma}=\sigma_{0}+H\left(\bar{\varepsilon}_{p}\right)=\sigma_{0}+K\left(1-\exp \left(\bar{\varepsilon}_{p}^{n}\right)\right)
$$

Where $\sigma_{0}$ is the initial yield stress, $\bar{\varepsilon}_{p}$ is the equivalent plastic strain and $K$ and $n$ are material constants.

The strain-rate influence on the plastic flow curve, described by the function $V(\dot{\bar{\varepsilon}})$, can be introduced in a multiplicative or additive way on the general strain hardening law. According to the coupling effects, four types of rate-dependent hardening model have been identified by Paul [32]. These models are summed up below (Eq. 3 to 6):

$$
\begin{aligned}
& \text { Type } 1: \bar{\sigma}=\sigma_{0}+H\left(\bar{\varepsilon}_{p}\right) \cdot V(\dot{\bar{\varepsilon}}) \\
& \text { Type } 2: \bar{\sigma}=\sigma_{0} \cdot V(\dot{\bar{\varepsilon}})+H\left(\overline{\varepsilon_{p}}\right) \\
& \text { Type } 3: \bar{\sigma}=\left(\sigma_{0}+H\left(\bar{\varepsilon}_{p}\right)\right) \cdot V(\dot{\bar{\varepsilon}}) \\
& \text { Type } 4: \bar{\sigma}=\sigma_{0} \cdot V_{1}(\dot{\bar{\varepsilon}})+H\left(\bar{\varepsilon}_{p}\right) \cdot V_{2}(\dot{\bar{\varepsilon}})
\end{aligned}
$$

In those models strain and strain-rate hardening parameters can be linear or non-linear functions of temperature. In this work, deformation-induced thermal effects are not considered, even if these phenomena could be significant at tested strain rates which are closed to the adiabatic limit for typical steel [31]. The purpose of the current work being to validate a new dynamic experimental device in order to investigate the rate-dependent behaviour of metallic alloys under biaxial loadings, the flow stress temperature sensitivity is considered as a secondary material factor in this study.

Classically, behaviour of many metallic alloys is described by Type 1 models assuming the independency of the initial yield stress to the strain rate.

Concerning the DP600 steel grade, Yu [33] have proposed a hardening model on the basis of Khan-Huang (KH) model [34] by neglecting the influence of strain rate on the strain hardening term (Type 2) as follows:

$$
\bar{\sigma}=\sigma_{0}\left[1+D\left(\ln \frac{\dot{\bar{\varepsilon}}}{\dot{\bar{\varepsilon}}_{0}}\right)^{m}\right]+E_{\infty} \bar{\varepsilon}_{p}-a e^{\left(-\alpha \bar{\varepsilon}_{p}\right)}
$$

The strain-rate dependency of the modified model is applied only on the initial yield stress though it was applied on both initial yield stress and strain hardening in the initial KH model (Type 3). This modified model describes well the hardening behaviour for DP600 steel at the strain rates from $10^{-4} s^{-1}$ to $10^{3} s^{-1}$. In this model, $\sigma_{0}, E_{\infty}, a, \alpha$ and $m$ are the material parameters and the reference strain rate is $\dot{\bar{\varepsilon}}_{0}=10^{6} \mathrm{~s}^{-1}$.

In [34], Paul proposed a hardening model with different strain rate dependencies on the initial yield stress and the strain hardening term as follows (Type 4): 


$$
\bar{\sigma}=\sigma_{0}\left[1+A \ln \left(\frac{\dot{\bar{\varepsilon}}}{\dot{\bar{\varepsilon}}_{0}}\right)+K \sqrt{\frac{\overline{\bar{\varepsilon}}}{\overline{\bar{\varepsilon}}_{0}}}\right]+\left[B \bar{\varepsilon}_{p}+C\left(1-e^{-\beta \bar{\varepsilon}_{p}}\right)\right]\left[1-G \ln \left(\frac{\dot{\bar{\varepsilon}}}{\dot{\bar{\varepsilon}}_{0}}\right)-H \sqrt{\frac{\dot{\bar{\varepsilon}}}{\dot{\bar{\varepsilon}}_{0}}}\right]
$$

$A, K, B, C, \beta, G$ and $H$ are the material parameters. This model has been validated to describe the strain rate influence on both the initial yield stress and strain hardening term for DP600 steel sheets in the strain rate range from $0.0007 s^{-1}$ to $250 s^{-1}$.

Based on observations of experimental uniaxial true-stress versus plastic strain curves (Fig. 1) and recent published works on this grade (cited above), a general formulation of the constitutive law assuming both a strain-rate dependency on the initial yield stress and the strain hardening seems to be well adapted to describe the hardening behavior of DP600 steel sheets. Here, a constitutive hardening law (Type 4) with two different strain rate dependency terms, $V_{1}(\dot{\bar{\varepsilon}})$ and $V_{2}(\dot{\bar{\varepsilon}})$, respectively on the initial yield stress and the strain hardening is chosen. For these two terms, a power model is adopted to describe the strain rate sensitivity:

$$
V_{1}(\dot{\bar{\varepsilon}})=\dot{\bar{\varepsilon}}^{m_{1}} \text { and } V_{2}(\dot{\bar{\varepsilon}})=\dot{\bar{\varepsilon}}^{m_{2}}
$$

Where $m_{1}$ and $m_{2}$ are the strain rate sensitivity parameters.

\subsection{Calibration of strain-rate dependent hardening laws from uniaxial tensile tests}

Parameters of the strain rate dependent hardening laws are obtained by minimizing the error function $\delta$ expressed below (Eq. 10). The calculated stresses are determined from the analytical model of the homogeneous uniaxial tensile test.

$$
\delta=\sum_{j=1}^{p} \delta_{j}=\sum_{j=1}^{p}\left(\frac{1}{q} \sum_{i=1}^{q} \sqrt{\left(\frac{\bar{\sigma}^{c a l}\left(\bar{\varepsilon}_{p}^{\exp , i, j}\right)-\bar{\sigma}^{\exp }\left(\bar{\varepsilon}_{p}^{\exp , i, j}\right)}{\bar{\sigma}^{\exp }\left(\varepsilon_{p}^{\exp , i, j}\right)}\right)^{2}}\right)
$$

Where $p$ is the number of true stress-plastic strain curves (or number of tests in the experimental database), $q$ is the point number on each curve, $\bar{\sigma}^{c a l}$ and $\bar{\sigma}^{\exp }$ are respectively the analytical and experimental equivalent true-stress.

The identified parameters on the basis of Ludwick's law are presented in Table 1. As it can be seen, both initial yield stress and hardening behaviour are strain rate dependent. As shown in the literature, it seems that initial yield stress is more sensitive than strain hardening to the strain rate $\left(m_{1}>m_{2}\right)$, nevertheless, as observed in Fig. 2, the best set of parameters for the Ludwick's formulation leads to an over-estimation of the hardening level at low strains. 


\section{ACCEPTED MANUSCRIPT}

Tab. 1 Identified material parameters of rate-dependent Ludwick's law from uniaxial tests

$$
\bar{\sigma}=\sigma_{0} \dot{\bar{\varepsilon}}^{m_{1}}+K \bar{\varepsilon}_{p}^{n} \dot{\bar{\varepsilon}}^{m_{2}} \quad \text { Error } \delta(\%)
$$

\begin{tabular}{cccccc}
\hline$\sigma_{0}(\mathrm{MPa})$ & $K(\mathrm{MPa})$ & $n$ & $m_{1}$ & $m_{2}$ & \multirow{2}{*}{6.53} \\
\cline { 1 - 5 } 351.6 & 1079.4 & 0.47 & 0.0223 & 0.0044 &
\end{tabular}

The identified parameters on the basis of Voce's law are presented in Table 2. As observed on Fig. 2, a better fit is obtained with Voce's formulation than with Ludwick's one which is confirmed by error function values $\delta$ which are respectively $6.53 \%$ and $3.85 \%$ for Ludwick's and Voce's formulations. Both the initial yield stress and the strain hardening term are observed to be strain-rate dependent. Nevertheless, Voce's formulation gives close values of sensitivity indexes $m_{1}=0.0137$ and $m_{2}=0.0123$, with a higher sensitivity observed on the yield stress than on the strain hardening.

Tab. 2 Identified material parameters of rate-dependent Voce's law from uniaxial tests

\begin{tabular}{cccccc} 
& $\bar{\sigma}=\sigma_{0} \dot{\bar{\varepsilon}}^{m_{1}}+K\left(1-\exp \left(-n \bar{\varepsilon}_{p}\right)\right) \dot{\bar{\varepsilon}}^{m_{2}}$ & & & \multirow{2}{*}{ Error $\delta(\%)$} \\
\cline { 1 - 4 }$\sigma_{0}(\mathrm{MPa})$ & $K(\mathrm{MPa})$ & $n$ & $m_{1}$ & $m_{2}$ & 3.85 \\
\cline { 1 - 4 } 392.4 & 432.4 & 14.45 & 0.0137 & 0.0123 & \\
\hline
\end{tabular}

The identified flow stress curves on the basis of Ludwick's and Voce's laws are compared with the experimental ones at each strain rate, as shown in Fig. 2.

It can be seen that all identified flow stress curves are in relatively good agreement with experimental ones. Nevertheless, the Voce's formulation is closer to the experimental results than the Ludwick's one. This last formulation leads to a slight over-estimation for small strains (under 5\%) and for large strains (up to $13 \%$ ). 


\section{ACCEPTED MANUSCRIPT}
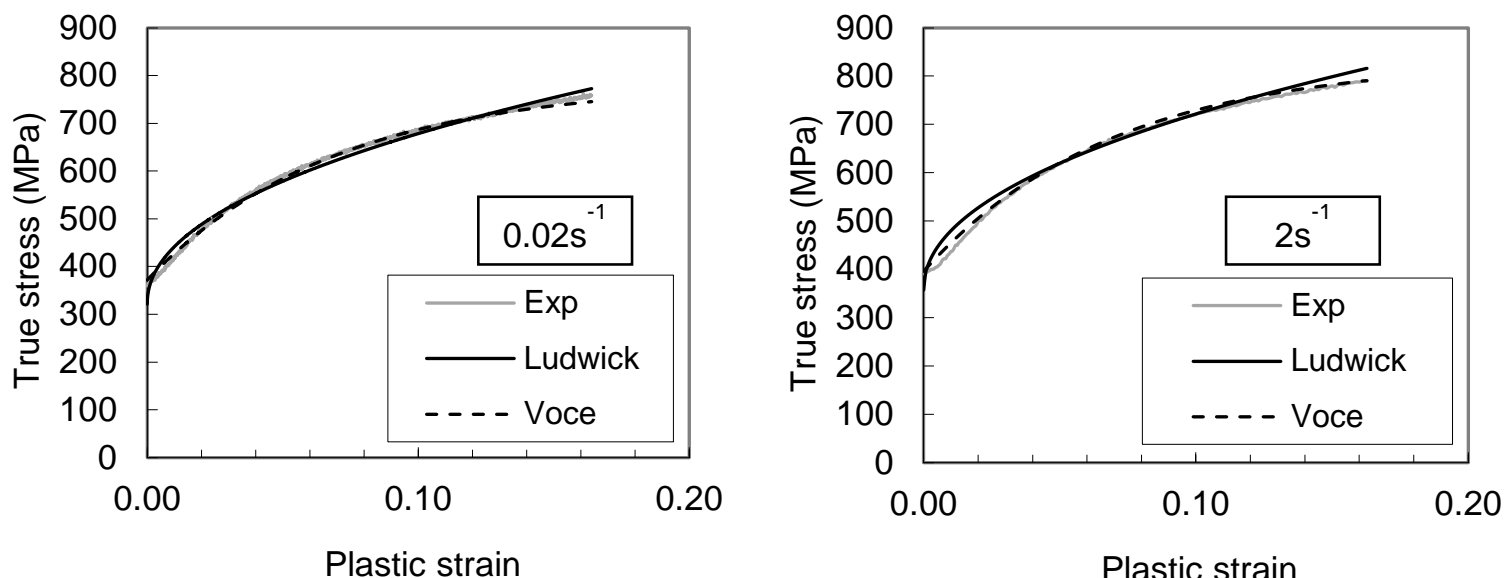

Plastic strain
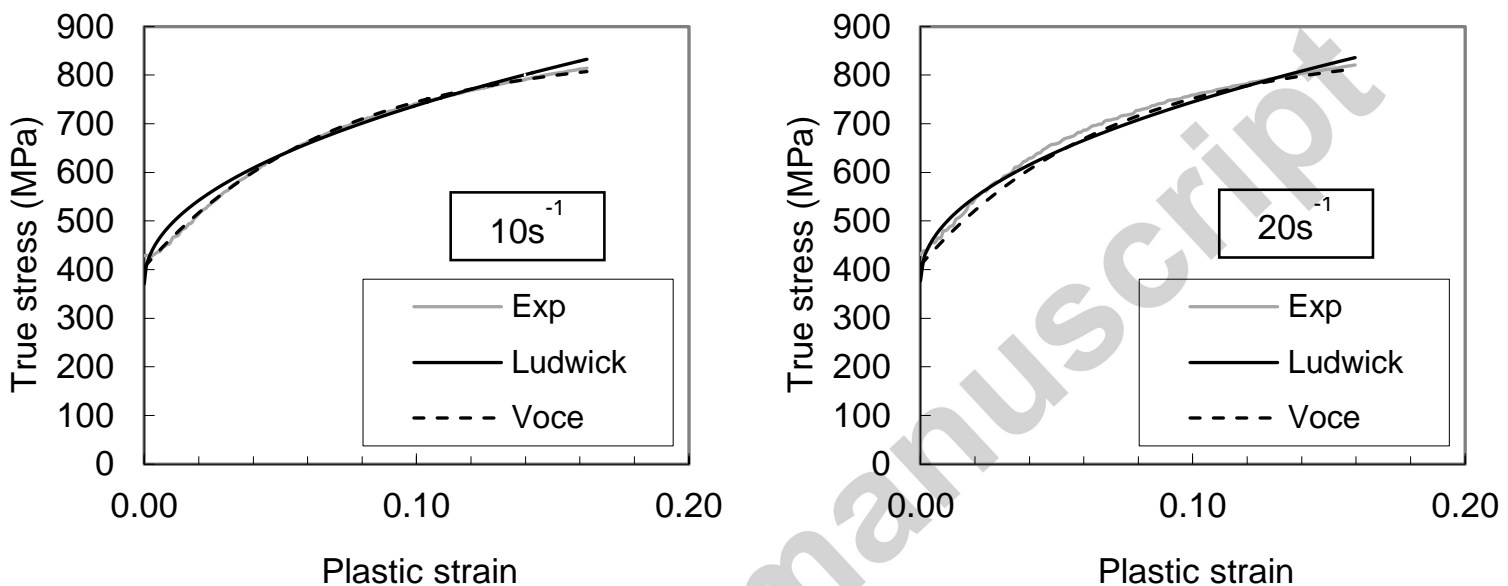

Fig. 2 Comparison of experimental and identified flow curves from uniaxial tensile tests

For the two analytical models (Ludwick's and Voce's) calibrated from experimental uniaxial tensile tests in an equivalent plastic strain ranging up to $17 \%$, the equivalent stress versus equivalent plastic strain curves are plotted for an equivalent plastic strain range extrapolated up to 0.3 (Fig. 3). These two formulations are compared at three strain rates $10^{-3} s^{-1}, 10^{-1} s^{-1}$ and $10^{1} s^{-1}$. As shown in this figure, these two models give very different trends. The identified material parameters for the Voce's formulation lead to a complete saturation of the strain hardening for deformation between $17 \%$ and $30 \%$. As contrary, Ludwick's model, identified on the same experimental data, shows a constant increase of the flow stress for large strains (between 15 and 30\%). As one can see it, it is difficult to define the best formulation for large strains on the only base of uniaxial tensile tests. 


\section{ACCEPTED MANUSCRIPT}

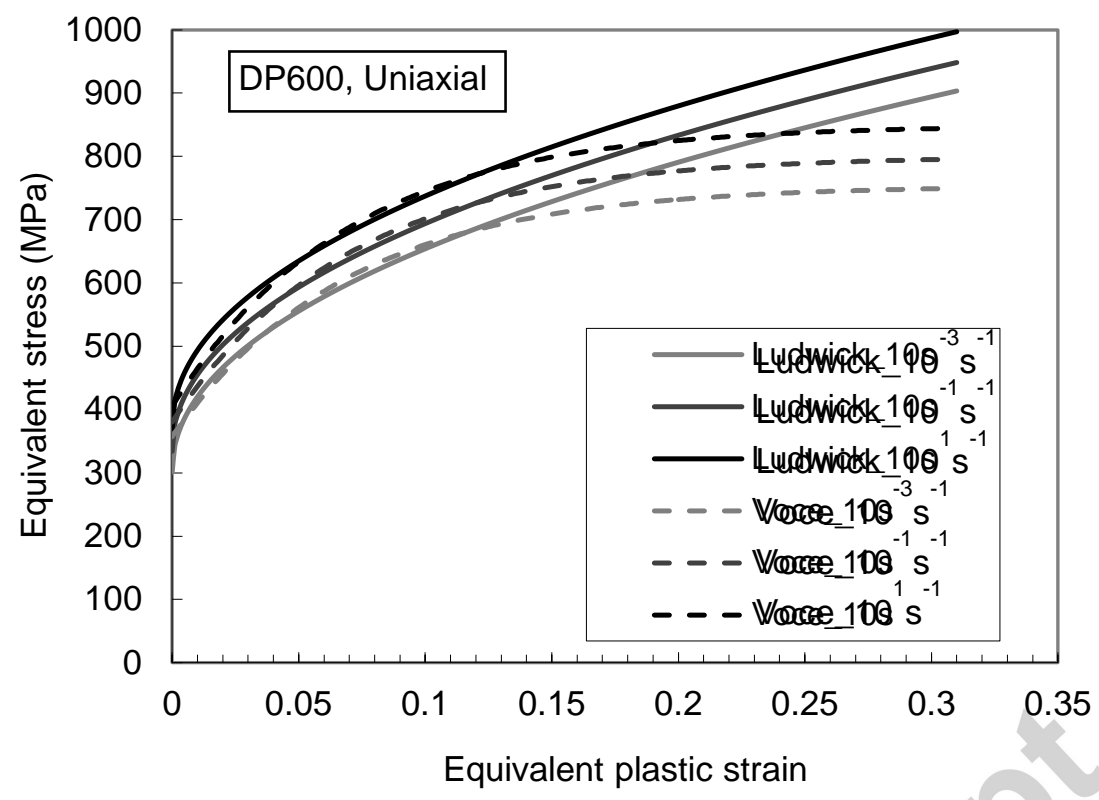

Fig. 3 Strain rate dependent hardening law identified by uniaxial tests

\section{Biaxial tensile tests}

In this section, the quasi-static and dynamic biaxial tensile tests on cruciform specimens are performed to obtain large strains at the central zone.

\subsection{Testing specimen and experiments}

Recently, for static characterizations, Kuwabara [37] has proposed a standard cruciform shape to determine elastic constants or 2D initial yield surfaces of metallic sheet under in-plane biaxial loadings. This shape is only suitable for low strain levels and no standard specimen exists for large strains. To allow characterizations for large strains, Zidane et al. [24] have proposed a specific cruciform shape to determine forming limit curves (FLC) of metallic sheet. In this specimen, a central thickness reduction is defined by a curved profile to obtain the onset of necking at the central point. 


\section{ACCEPTED MANUSCRIPT}

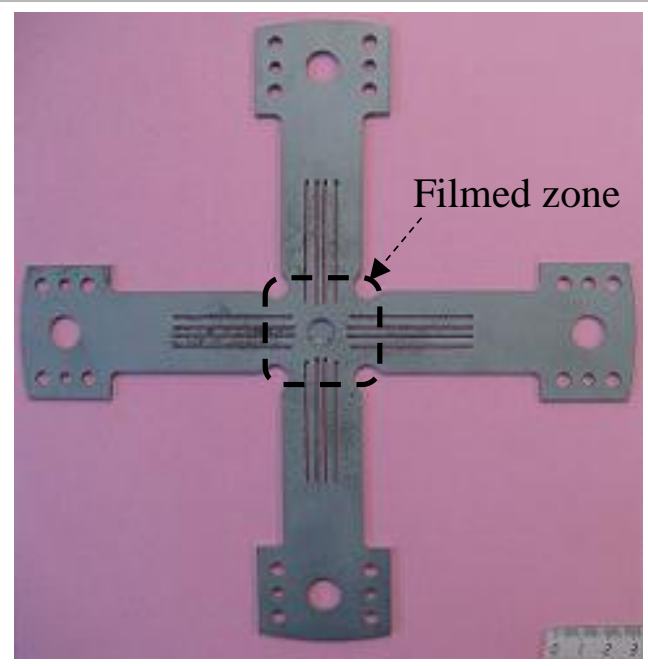

Fig. 4 Cruciform specimen of DP600

In the present study, a cruciform shape with a flat central zone of reduced thickness to localize the deformation, four slits in each arm to reduce the transverse rigidity, notches at the intersections of arms to reduce the localisation is optimized as shown in Fig. 4. This shape has been validated for large strains and static applications by present authors in previous works [10] for the determination of hardening law parameters. The sample thickness outside the thinned zone is $2 \mathrm{~mm}$. The final thickness in the central zone of the specimen is $0.625 \mathrm{~mm}$. The specimen is manufactured in DP600 steel sheet by milling the central zone and by wire cutting the slits.

As explained above, the biaxial machine (Fig. 5) is equipped with four independent servohydraulic actuators. Each end of the cruciform specimen is connected to an actuator rod through a mechanical part assembly as shown (for only one specimen end) in Fig. 6. For dynamic tests, the impactor is accelerated along the sliding bar to obtain the specific velocity $V_{\text {impactor }}$ before the specimen is loaded. Due to the initial impact, oscillations appear on force signal measured by the load sensor (see Fig. 6). To reduce these oscillations a $3 \mathrm{~mm}$ thick elastomer damping layer is placed at the interface between the sliding bar and impactor. The thickness of the damping layer has been determined by mean of numerical simulations. These simulations are based on a FE model of the equi-biaxial tensile test including the mechanical part assembly presented Fig. 6, under dynamic conditions. After the impact, the displacement of the sliding bar is transmitted to each specimen end through the load sensor and the bi-articulated link. During the test, the velocity is maintained almost constant due to the inertia effect of impactor. The experimental forces along the two perpendicular directions are measured by deformation gauge load sensors. 


\section{ACCEPTED MANUSCRIPT}

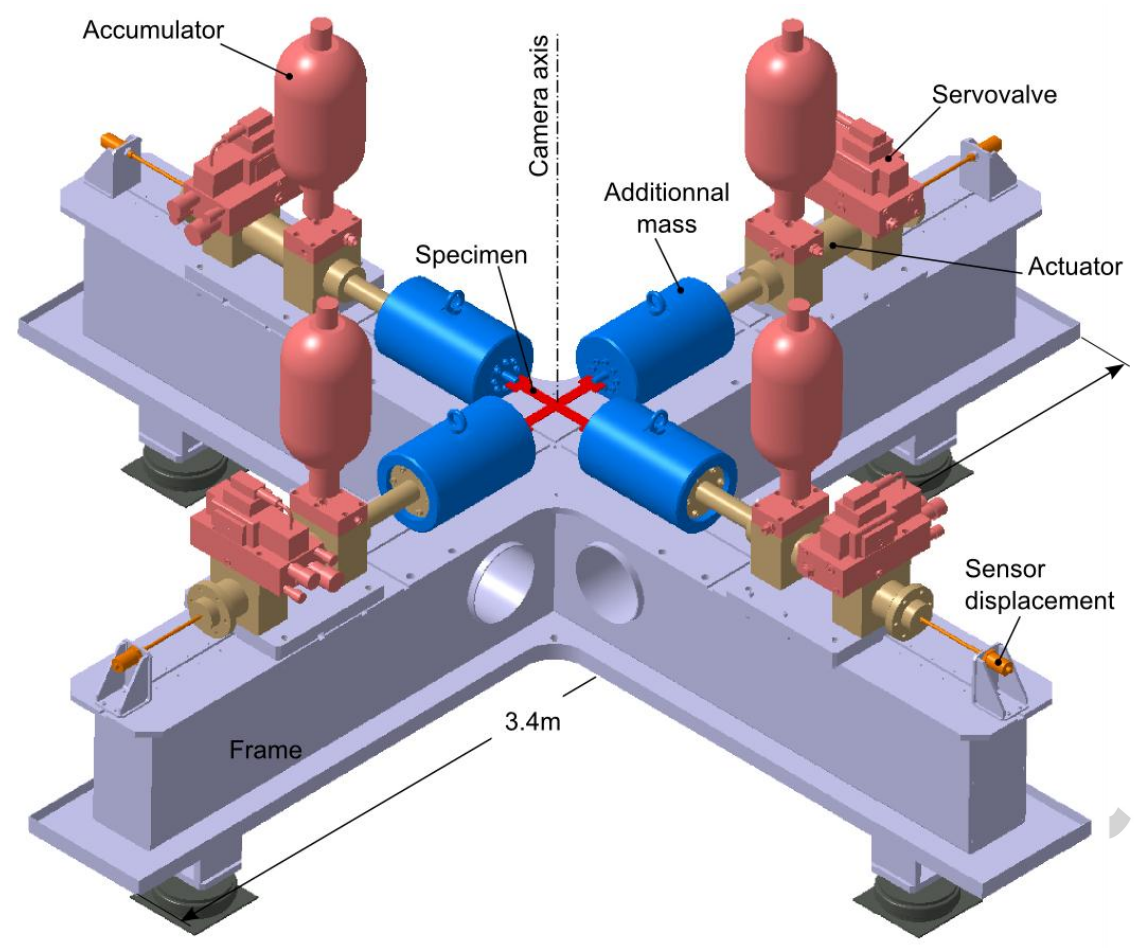

Fig. 5 Biaxial testing machine

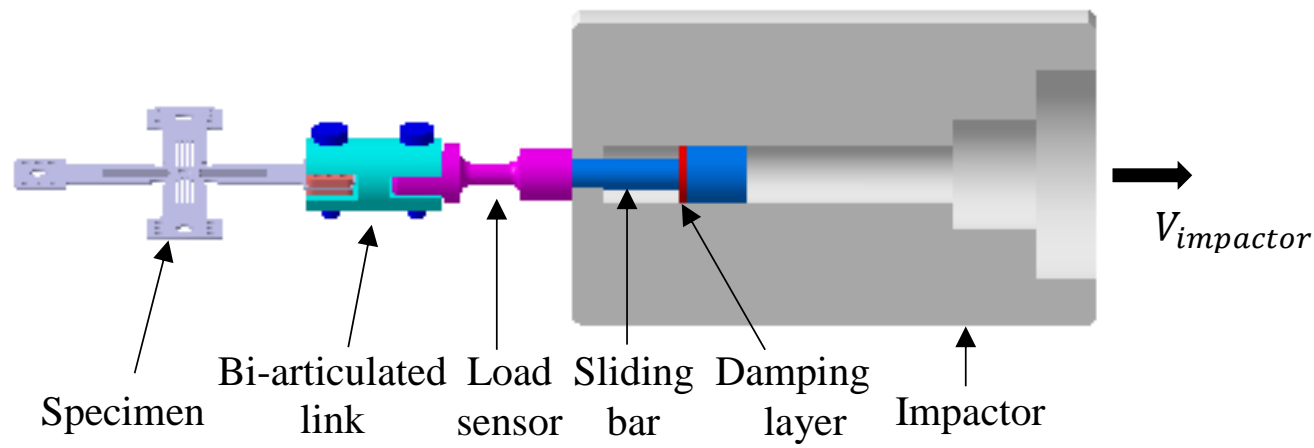

Fig. 6 Dynamic biaxial device with damping layer

\subsection{Experimental results}

Quasi-static and dynamic biaxial tensile tests on cruciform specimens are carried out at three loading speeds: $0.02 \mathrm{~mm} / \mathrm{s}, 1 \mathrm{~mm} / \mathrm{s}, 250 \mathrm{~mm} / \mathrm{s}$. A high speed camera is used to record the deformation of the central zone of specimen. The acquisition rate is respectively $50 \mathrm{f} / \mathrm{s}, 250 \mathrm{f} / \mathrm{s}$ and $18000 \mathrm{f} / \mathrm{s}$ for the three test velocities $0.02 \mathrm{~mm} / \mathrm{s}, 1 \mathrm{~mm} / \mathrm{s}, 250 \mathrm{~mm} / \mathrm{s}$. The acquisitions of the load sensor signals and the video images from the camera are synchronized. About 100 specimen images, before initial crack in the central zone, are used for DIC treatment for each specimen. Details on DIC parameters are given in [10]. Considering the image resolution and the dimensions of the filmed zone, a resolution of $0.037 \mathrm{~mm} / \mathrm{pixel}$ is obtained. For a velocity of $250 \mathrm{~mm} / \mathrm{s}$, Fig. 7, 8 and 9 show 


\section{ACCEPTED MANUSCRIPT}

respectively the displacement vectors in the same central zone, the onset of cracks and the equivalent strain field just before the initial crack happens. In the central zone $(-1 \mathrm{~mm} \leq x, y \leq 1 \mathrm{~mm})$, the strain field is rather homogeneous and the equivalent strain level reaches up to $30 \%$. The deformation localisation occurs near the points $(x=0, y= \pm 3 \mathrm{~mm})$. The evolution of equivalent strain, major and minor principal strains at the central point of the specimen are shown in Fig. 10 for the three velocities. To get robust values of principal strains near the central point $(x=y=0 \mathrm{~mm})$ of the specimen, the principal strains are averaged as follows:

$$
\varepsilon(t)=\frac{1}{p \times q} \sum_{i=1}^{p} \sum_{j=1}^{q} \varepsilon(i, j, t)
$$

where $p$ and $q$ are the numbers of points to be averaged in each direction and $\mathrm{t}$ is the time. Here, the average strains are calculated for $p=q=3$, corresponding to a square area defined by $-0.6 \mathrm{~mm} \leq x, y \leq 0.6 \mathrm{~mm}$.

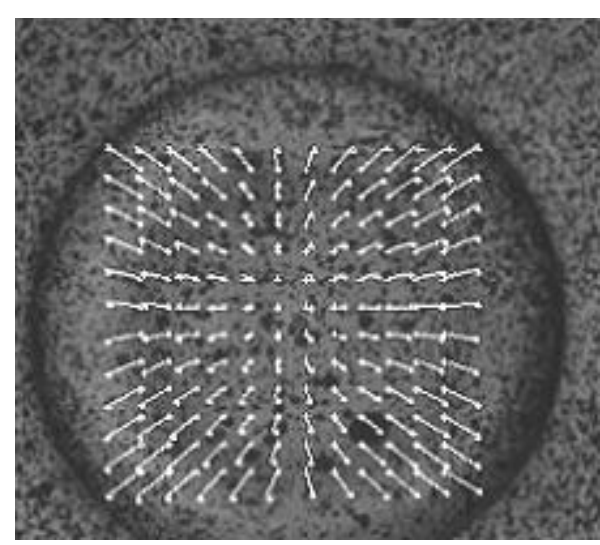

Fig. 7 Displacement vectors at $250 \mathrm{~mm} / \mathrm{s}$

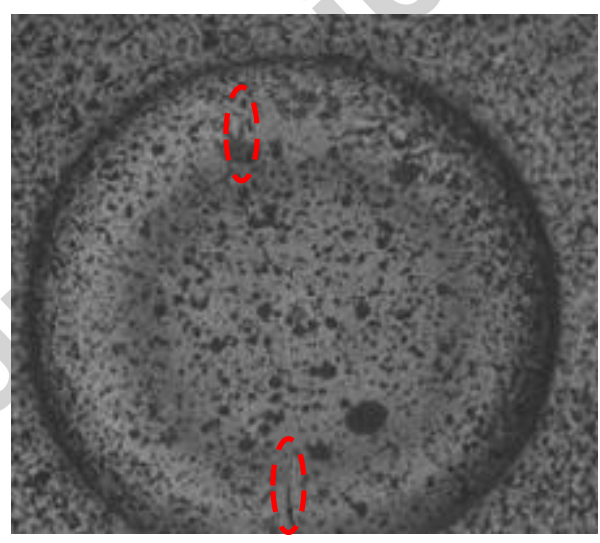

Fig. 8 Initial cracks at $250 \mathrm{~mm} / \mathrm{s}$

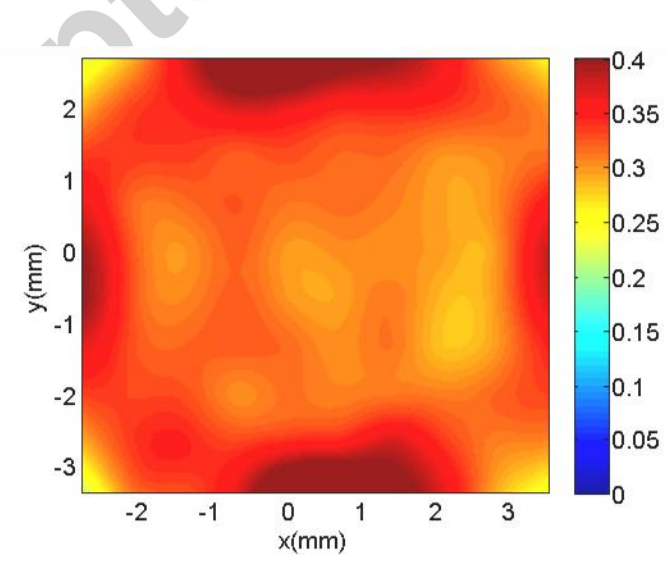

Fig. 9 Equivalent strain field in the central zone at $250 \mathrm{~mm} / \mathrm{s}(\mathrm{t}=15.5 \mathrm{~ms})$

Maximum value of $50 \%$ of the equivalent plastic strain is reached for the tensile test velocity of $0.02 \mathrm{~mm} / \mathrm{s}$ (Fig. 10a) and this value is about $40 \%$ for the velocities of $1 \mathrm{~mm} / \mathrm{s}$ and $250 \mathrm{~mm} / \mathrm{s}$ (Fig. 


\section{ACCEPTED MANUSCRIPT}

$10 \mathrm{~b}$ and Fig. 10c). Due to a little desynchronization between the two directions and material anisotropy, major principal strain curves does not exactly coincide with the minor principal strain curves. The major and minor principal strains are close to $20 \%$ for the two first tested velocities, with a maximum variation of $5 \%$ between the major and minor strain just before rupture. Due to a higher desynchronization, this variation is about $10 \%$ for the last tested configuration at $250 \mathrm{~mm} / \mathrm{s}$.

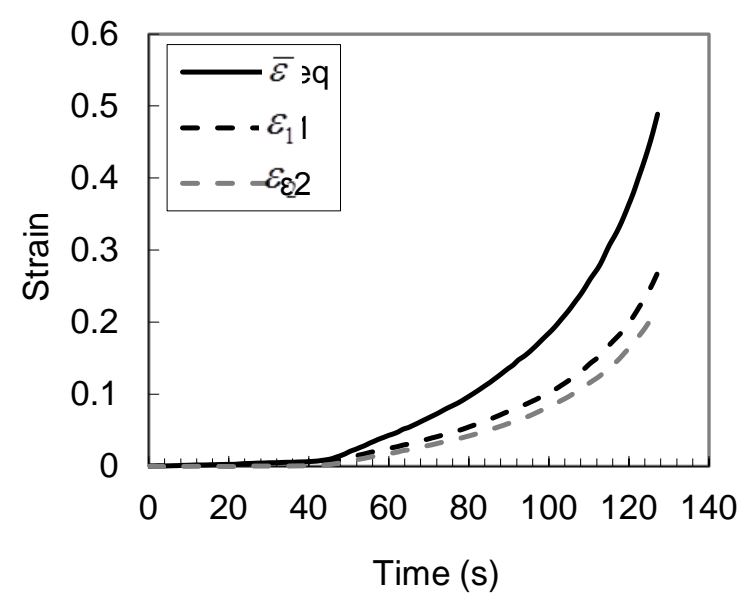

(a) $0.02 \mathrm{~mm} / \mathrm{s}$

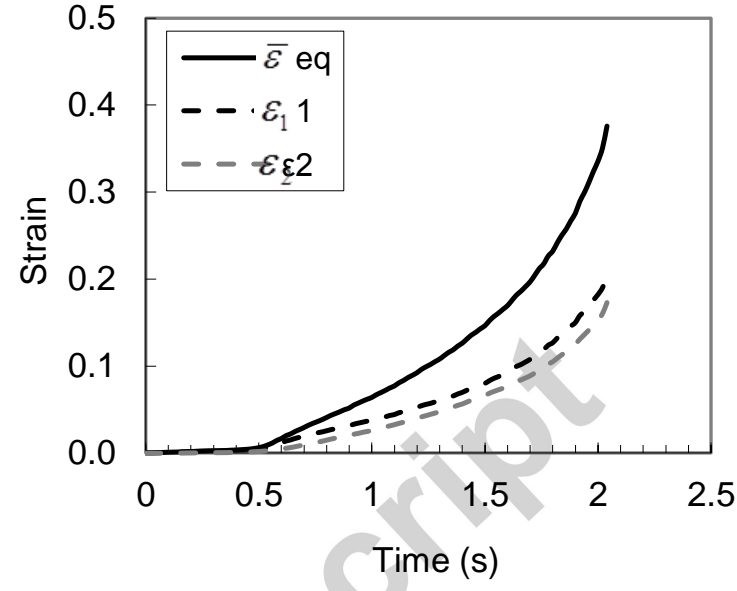

(b) $1 \mathrm{~mm} / \mathrm{s}$

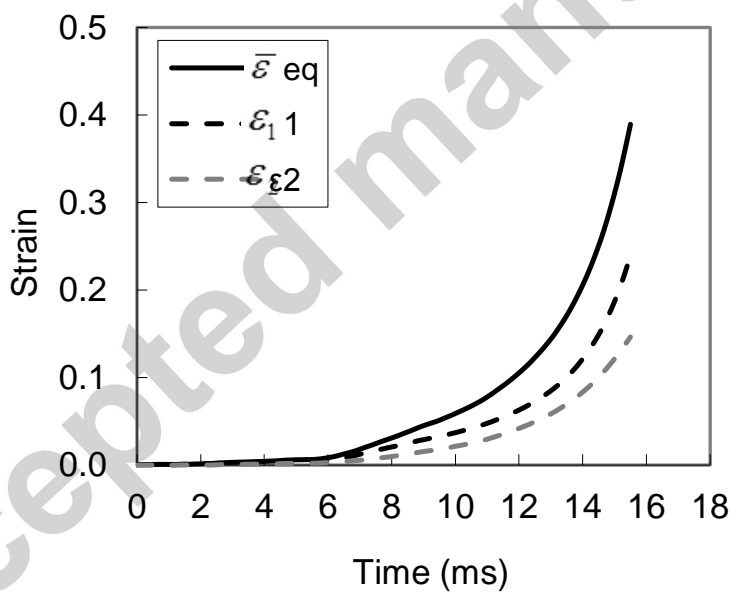

(c) $250 \mathrm{~mm} / \mathrm{s}$

Fig. 10 Evolution of equivalent and principal strains at central point

The evolution of strain rate at the central point is presented in Fig. 11. For the loading velocity of $0.02 \mathrm{~mm} / \mathrm{s}$, from time $t=50 \mathrm{~s}$ up to the end, the strain rate varies from about $0.0025 \mathrm{~s}^{-1}$ to $0.02 \mathrm{~s}^{-1}$. The strain rate increases quickly after $t=120 \mathrm{~s}$ due to the strain localisation in the central zone. For the loading velocity of $1 \mathrm{~mm} / \mathrm{s}$, the strain rate increases from $0.1 \mathrm{~s}^{-1}$ to $0.7 \mathrm{~s}^{-1}$ for 


\section{ACCEPTED MANUSCRIPT}

a time $0.6 s \leq t \leq 2 s$. The loading velocity of $250 \mathrm{~mm} / \mathrm{s}$ leads to an increase of the strain rate from about $20 s^{-1}$ up to $170 s^{-1}$, for a time corresponding to $t=7 \mathrm{~ms}$ up to the end of the test.
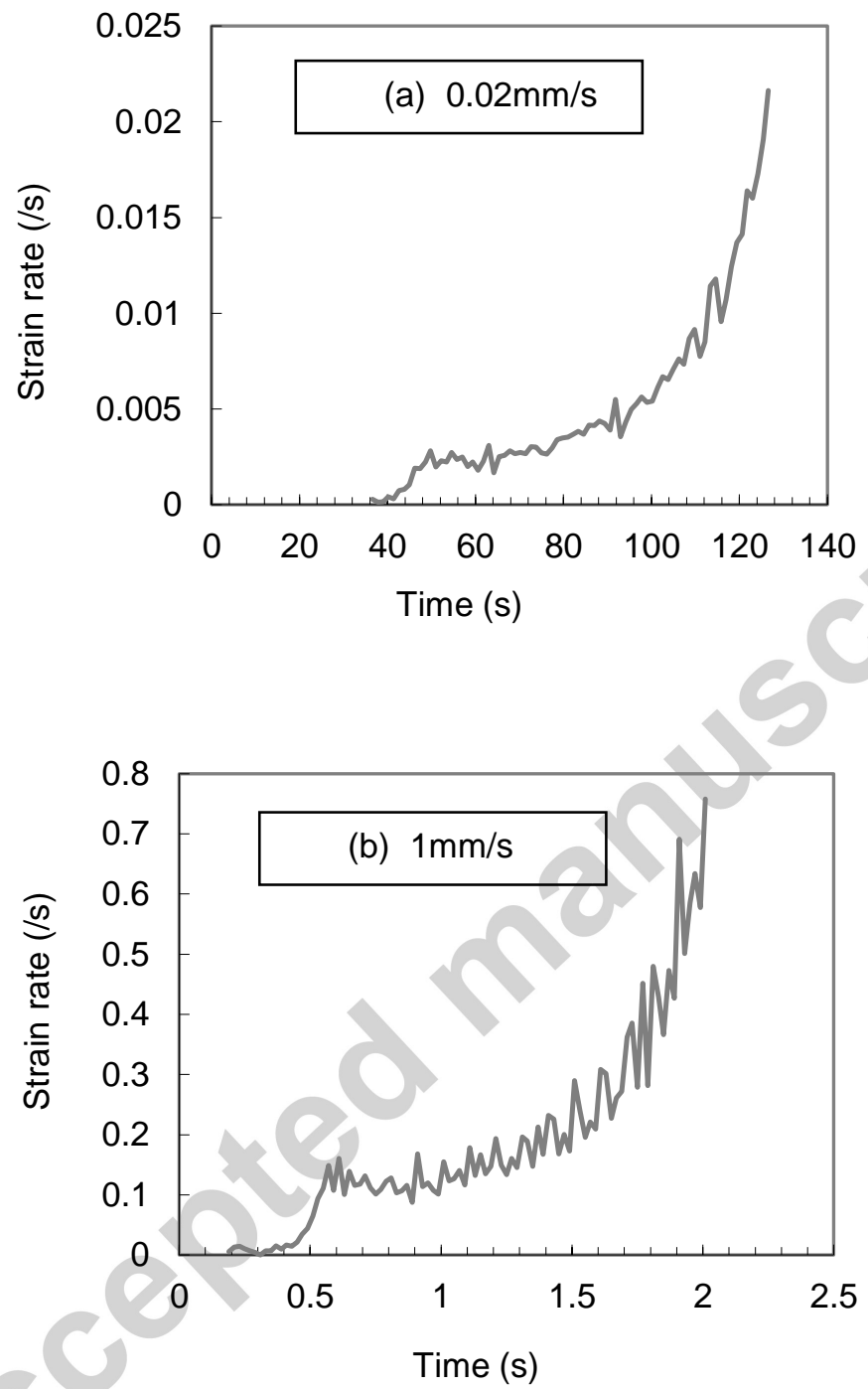


\section{ACCEPTED MANUSCRIPT}

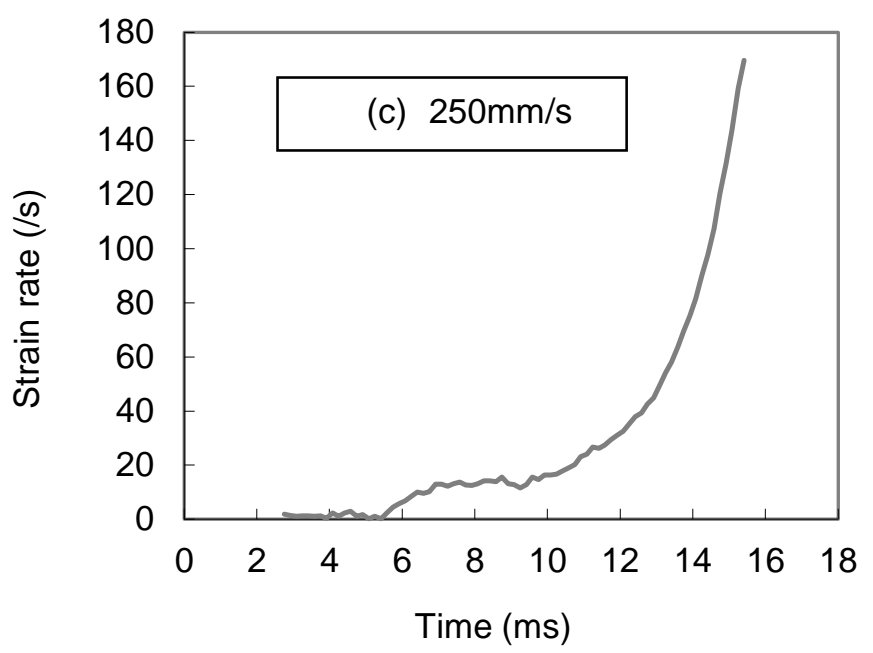

Fig. 11 Evolution of strain path and rate at central point

The experimental force curves have been measured along the two arms of specimens, as shown in Fig. 12. For the loading velocity of $0.02 \mathrm{~mm} / \mathrm{s}$, the forces along the two arms are well synchronized (at the beginning of test) whereas at $1 \mathrm{~mm} / \mathrm{s}$ a slight desynchronization (approximately $0.1 \mathrm{~s}$ ) of the two axes of the biaxial tensile testing machine can be observed. For the dynamic tests at $250 \mathrm{~mm} / \mathrm{s}$ (Fig. 12(c)), despite a desynchronization which can be evaluated to $0.4 m s$, the measured force curves don't present oscillations at the beginning of the test, showing the effectiveness of the damping layer.

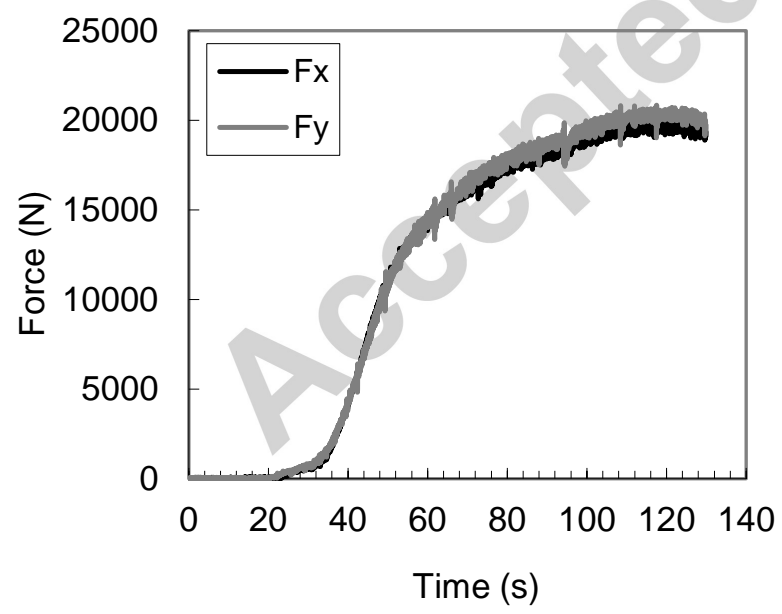

(a) $0.02 \mathrm{~mm} / \mathrm{s}$

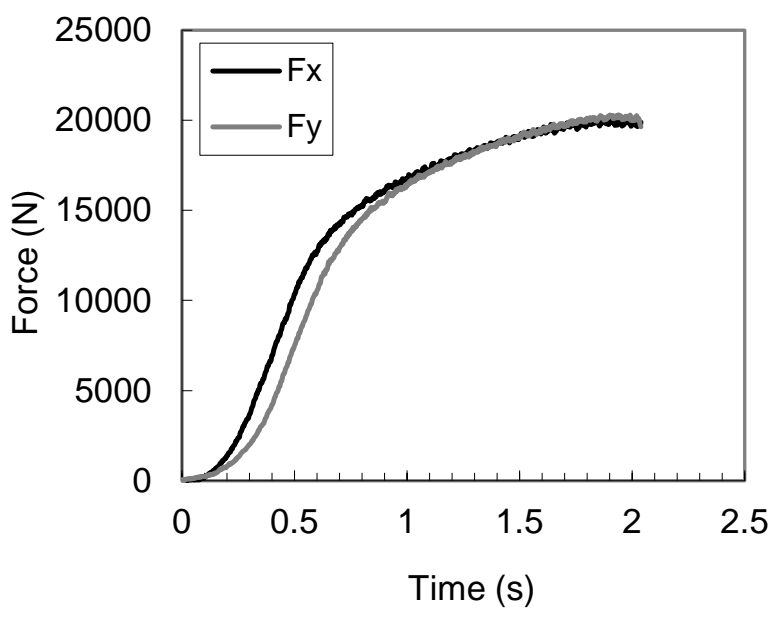

(b) $1 \mathrm{~mm} / \mathrm{s}$ 


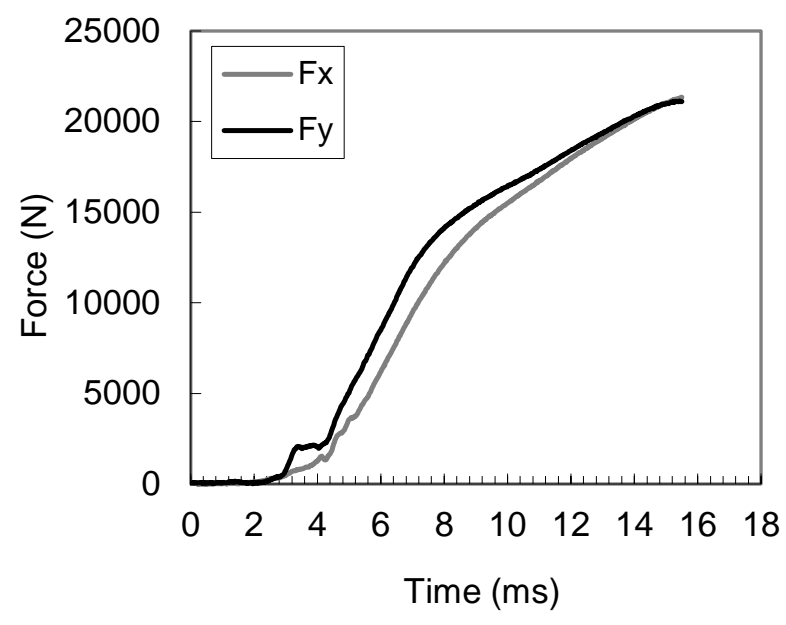

(c) $250 \mathrm{~mm} / \mathrm{s}$

Fig. 12 Experimental forces

\subsection{Identification of strain-rate dependent hardening parameters from biaxial tensile tests}

Calibration of strain-rate dependent hardening laws under dynamic biaxial loadings is proposed from an inverse procedure based on the FE simulation of the biaxial tensile test. Experimental data consists in the three equi-biaxial tensile tests at $0.02,1$ and $250 \mathrm{~mm} / \mathrm{s}$ presented above. Tensile force measurements along the two axes of the cross specimen are applied as boundary conditions in FE simulations. Experimental principal strains calculated at the central point of the specimen surface (Fig. 10) are compared with the simulated ones through an error function $Q$ :

$$
Q=\frac{1}{p} \sum_{k=1}^{p} Q_{k}=\frac{1}{2 p} \sqrt{\sum_{i=1}^{2}\left(\sum_{j=1}^{q}\left(\varepsilon_{i}^{\text {sim }}\left(t_{j}\right)-\varepsilon_{i}^{\exp }\left(t_{j}\right)\right)^{2} / \sum_{j=1}^{q}\left(\varepsilon_{i}^{\exp }\left(t_{j}\right)\right)^{2}\right)}
$$

where $q$ is the total number of time points and $p$ is the number of tests at different velocities, $\varepsilon_{1}^{\text {sim }}$ and $\varepsilon_{2}^{\text {sim }}$ are the simulated major and minor principal strains at the central zone of FE model, $\varepsilon_{1}^{\exp }$ and $\varepsilon_{2}^{\text {exp }}$ are the experimental principal strains in the same zone of the specimen (Fig. 10(a), (b), (c)). The error function $Q$ is evaluated through an optimization loop built in the software platform ModFrontier. The Simplex algorithm has been chosen to optimize the material parameters. In order to make sure that the global minimum is found, different sets of initial values have been tested. Identified material parameters correspond to the parameter set which minimizes the error function $Q$.

As explained in [10], FE simulations with solid elements (C3D4) are very time-consuming. So to keep simulation times compatible with the inverse procedure which requires many simulations, a FE model with 2D linear shell element mesh (S4R) is proposed. The shell model has been divided into three zones with different thicknesses obtained from successive simulations in order to obtain 


\section{ACCEPTED MANUSCRIPT}

close evolutions of the major and minor principal strain curves at the centre of the specimen for the two models.

For the isotropic elasticity, a Young's modulus of $E=200 G P a$ and a Poisson's ratio of $v=0.3$ are considered. Plastic behaviour of DP600 steel sheets is modelled assuming the associated normal flow rule and Hill 48 anisotropic yield criterion defined by :

$$
\psi\left(\sigma_{i j}\right)=\sqrt{F\left(\sigma_{22}-\sigma_{33}\right)^{2}+G\left(\sigma_{33}-\sigma_{11}\right)^{2}+H\left(\sigma_{11}-\sigma_{22}\right)^{2}+2\left(L \sigma_{23}{ }^{2}+M \sigma_{31}{ }^{2}+N \sigma_{12}{ }^{2}\right)}
$$

where $F, G, H, L, M$ and $N$ are the material parameters. These parameters, given in Table 3, have been determined from the three anisotropic coefficients $\left(r_{0}=0.89 ; r_{45}=0.85 ; r_{90}=1.12\right)$ proposed by Ozturk et al. [36]. The parameters of the yield function are supposed to be independent to the strain rate and strain level.

Tab. 3 Parameters of Hill 48 yield function

\begin{tabular}{cccccc}
\hline$F$ & $G$ & $H$ & $L$ & $M$ & $N$ \\
\hline 0.4204 & 0.5291 & 0.4709 & 1.5 & 1.5 & 1.2819 \\
\hline
\end{tabular}

The general strain rate dependent hardening laws on the basis of Ludwick and Voce formulations, already calibrated from uniaxial tensile tests in section 2.3 , are now identified from experimental biaxial tensile tests. The identified parameters are presented in Table 4 and Table 5 for respectively the Ludwick and Voce formulations. Contrary to the results observed from uniaxial tensile test calibration, the influence of strain rate on the strain hardening term is more important than the one on the initial yield stress $\left(m_{1}<m_{2}\right)$ for the two identified models.

Tab. 4 Identified material parameters of rate-dependent Ludwick law from biaxial tests

\begin{tabular}{|c|c|c|c|c|c|c|c|}
\hline \multicolumn{8}{|c|}{$\bar{\sigma}=\sigma_{0} \dot{\bar{\varepsilon}}^{m_{1}}+K \bar{\varepsilon}_{p}^{n} \dot{\bar{\varepsilon}}^{m_{2}}$} \\
\hline \multicolumn{2}{|l|}{$\sigma_{0}(\mathrm{MPa})$} & $K(\mathrm{MPa})$ & \multicolumn{2}{|c|}{$n$} & \multicolumn{2}{|c|}{$m_{1}$} & $m_{2}$ \\
\hline \multicolumn{2}{|l|}{339.2} & 839.7 & \multicolumn{2}{|c|}{0.3864} & \multicolumn{2}{|c|}{0.0052} & 0.0158 \\
\hline \multirow{3}{*}{ Error (\%) } & \multicolumn{2}{|c|}{$0.02 \mathrm{~mm} / \mathrm{s}$} & \multicolumn{2}{|c|}{$1 \mathrm{~mm} / \mathrm{s}$} & \multicolumn{2}{|c|}{$250 \mathrm{~mm} / \mathrm{s}$} & \\
\hline & $\delta\left(\varepsilon_{1}\right)$ & $\delta\left(\varepsilon_{2}\right)$ & $\delta\left(\varepsilon_{1}\right)$ & $\delta\left(\varepsilon_{2}\right)$ & $\delta\left(\varepsilon_{1}\right)$ & $\delta\left(\varepsilon_{2}\right)$ & $(\%)$ \\
\hline & 7. & 8.4 & 13.4 & 7.7 & 9.2 & 6.4 & 8.7 \\
\hline
\end{tabular}


Table 5 Identified material parameters of rate-dependent Voce law from biaxial tests

\begin{tabular}{|c|c|c|c|c|c|c|c|}
\hline \multicolumn{8}{|c|}{$\bar{\sigma}=\sigma_{0} \dot{\bar{\varepsilon}}^{m_{1}}+\left(1-\exp \left(-n \bar{\varepsilon}_{p}\right)\right) \dot{\bar{\varepsilon}}^{m_{2}}$} \\
\hline \multicolumn{2}{|l|}{$\sigma_{0}(\mathrm{MPa})$} & $K(\mathrm{MPa})$ & \multicolumn{2}{|c|}{$n$} & \multicolumn{2}{|c|}{$m_{1}$} & $m_{2}$ \\
\hline 437.9 & \multicolumn{2}{|r|}{446.2} & \multicolumn{2}{|c|}{8.24} & \multicolumn{2}{|c|}{0.0032} & 0.0245 \\
\hline \multirow{3}{*}{ Error $(\%)$} & \multicolumn{2}{|c|}{$0.02 \mathrm{~mm} / \mathrm{s}$} & \multicolumn{2}{|c|}{$1 \mathrm{~mm} / \mathrm{s}$} & \multicolumn{2}{|c|}{$250 \mathrm{~mm} / \mathrm{s}$} & \\
\hline & $\delta\left(\varepsilon_{1}\right)$ & $\delta\left(\varepsilon_{2}\right)$ & $\delta\left(\varepsilon_{1}\right)$ & $\delta\left(\varepsilon_{2}\right)$ & $\delta\left(\varepsilon_{1}\right)$ & $\delta\left(\varepsilon_{2}\right)$ & $(\%)$ \\
\hline & 8. & 9.8 & 10.4 & 8.9 & 11.2 & 9.5 & 9.6 \\
\hline
\end{tabular}

The simulated and experimental principal strains at the central point of the surface specimen have been compared as shown in Fig. 13. Although the simulated principal strains are lower than the experimental ones at the beginning of tests, the observed trends are in good agreement for principal strains above $4 \%$ whatever the hardening formulation.

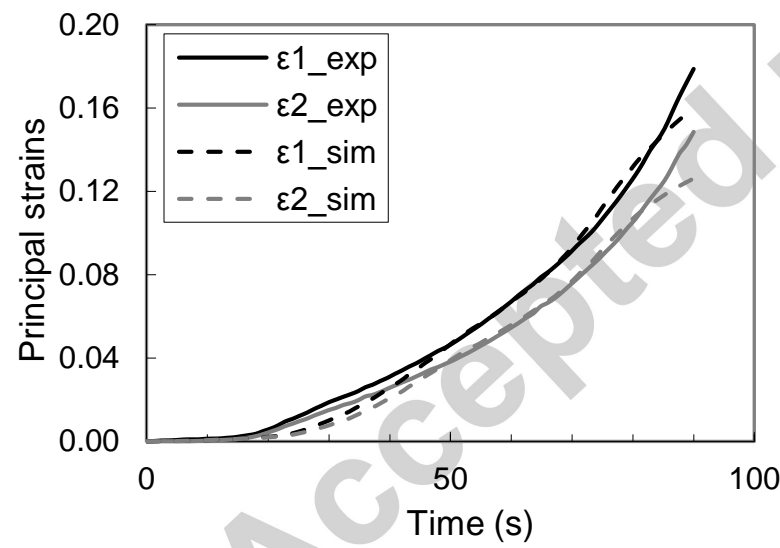

(a) $0.02 \mathrm{~mm} / \mathrm{s}$, Ludwick

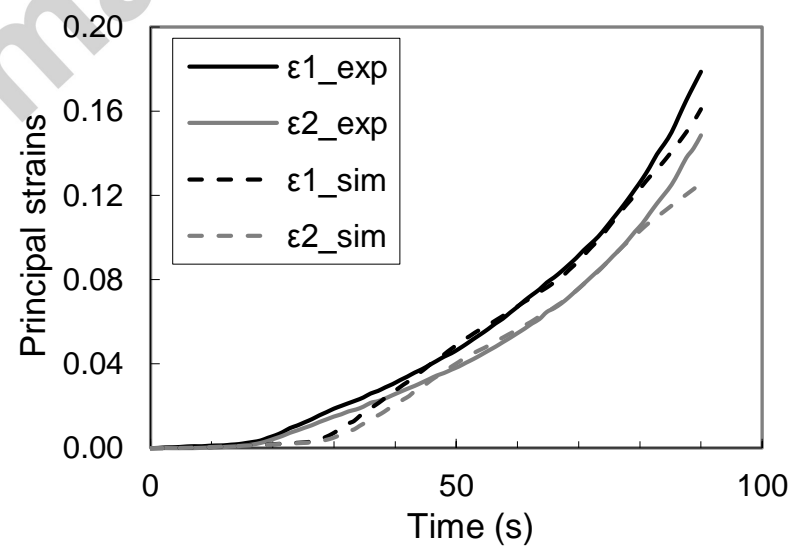

(b) $0.02 \mathrm{~mm} / \mathrm{s}$, Voce 


\section{ACCEPTED MANUSCRIPT}

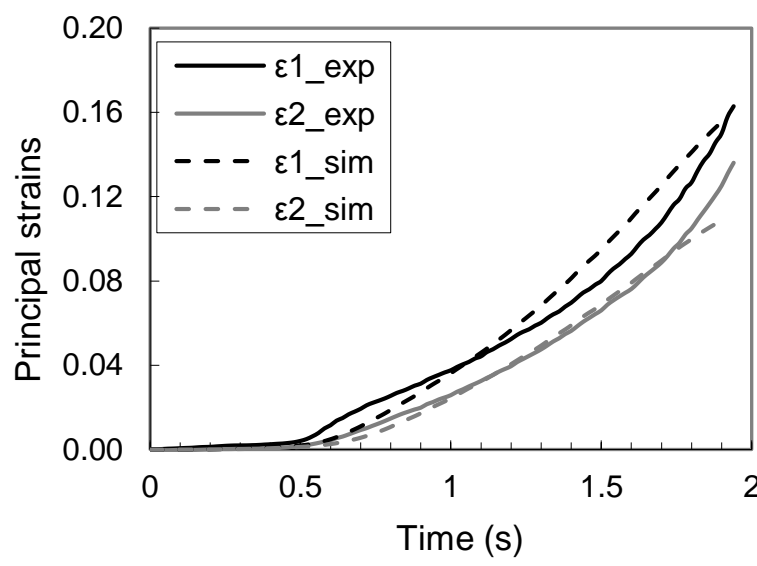

(c) $1 \mathrm{~mm} / \mathrm{s}$, Ludwick

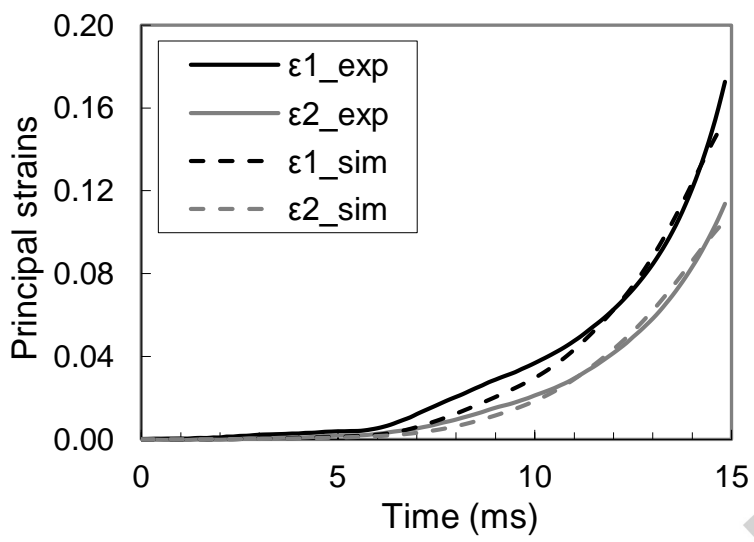

(e) $250 \mathrm{~mm} / \mathrm{s}$, Ludwick

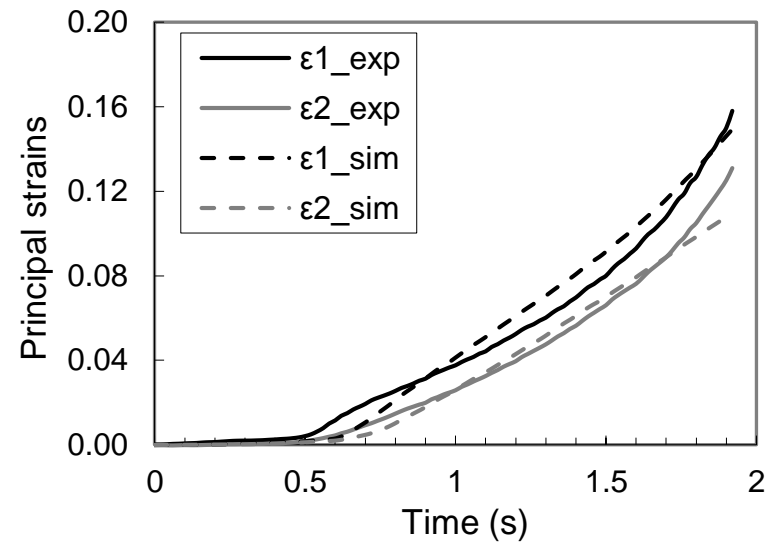

(d) $1 \mathrm{~mm} / \mathrm{s}$, Voce

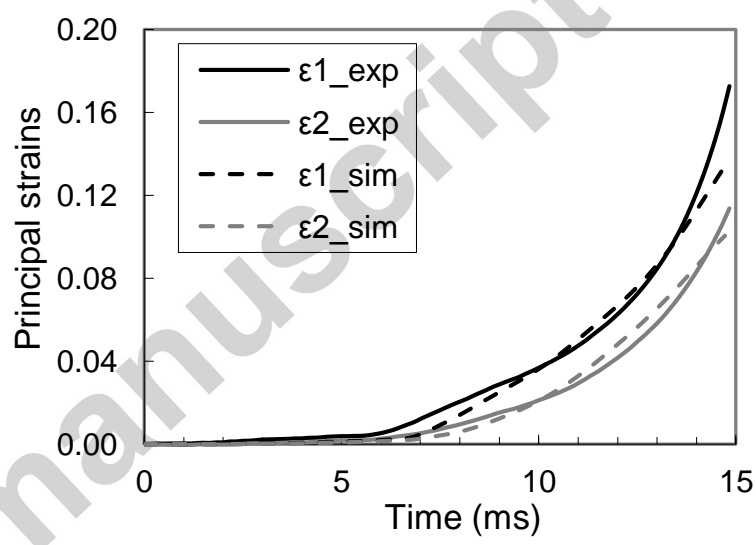

(f) $250 \mathrm{~mm} / \mathrm{s}$, Voce

Fig. 13 Comparison of experimental and simulated strain curves

The equivalent stress versus equivalent plastic strain curves identified on the basis of Ludwick's and Voce's models from the equi-biaxial tensile tests are compared in Fig. 14. For low strains, due to the difference observed on the values of the two initial yield stresses identified, significant differences can be raised between the two formulations. For larger strains (more than 5\%), the two formulations give approximately the same description of the strain-rate dependent hardening behaviour of DP600, even if some discrepancies appear for equivalent plastic strain close to $30 \%$. Comparison between Fig. 3 and Fig. 14, shows clearly the interest of the biaxial tensile test which permits a better strain and strain-rate hardening identification for large strains whatever the hardening formulation. If maximum values of the equivalent stress at $30 \%$ of equivalent plastic strain are compared for the Voce's formulation, one can notice that the strain rate sensitivity identified by mean of classical 


\section{ACCEPTED MANUSCRIPT}

uniaxial tensile characterizations or by biaxial tensile tests are closed. Nevertheless, the strain rate sensitivity predicted from biaxial tests is slightly higher. Voce's formulation at $30 \%$ of equivalent plastic strain, based on uniaxial characterizations, gives $\bar{\sigma}_{M a x}=750 M P a$ and $\bar{\sigma}_{M a x}=850 M P a$ for respectively a strain rate of $10^{-3} s^{-1}$ and $10^{1} s^{-1}$. Based on biaxial characterizations, for the same strain rate range, the maximum equivalent stress varies between $\bar{\sigma}_{\operatorname{Max}}=775 \mathrm{MPa}$ and $\bar{\sigma}_{\operatorname{Max}}=$ $875 M P a$.

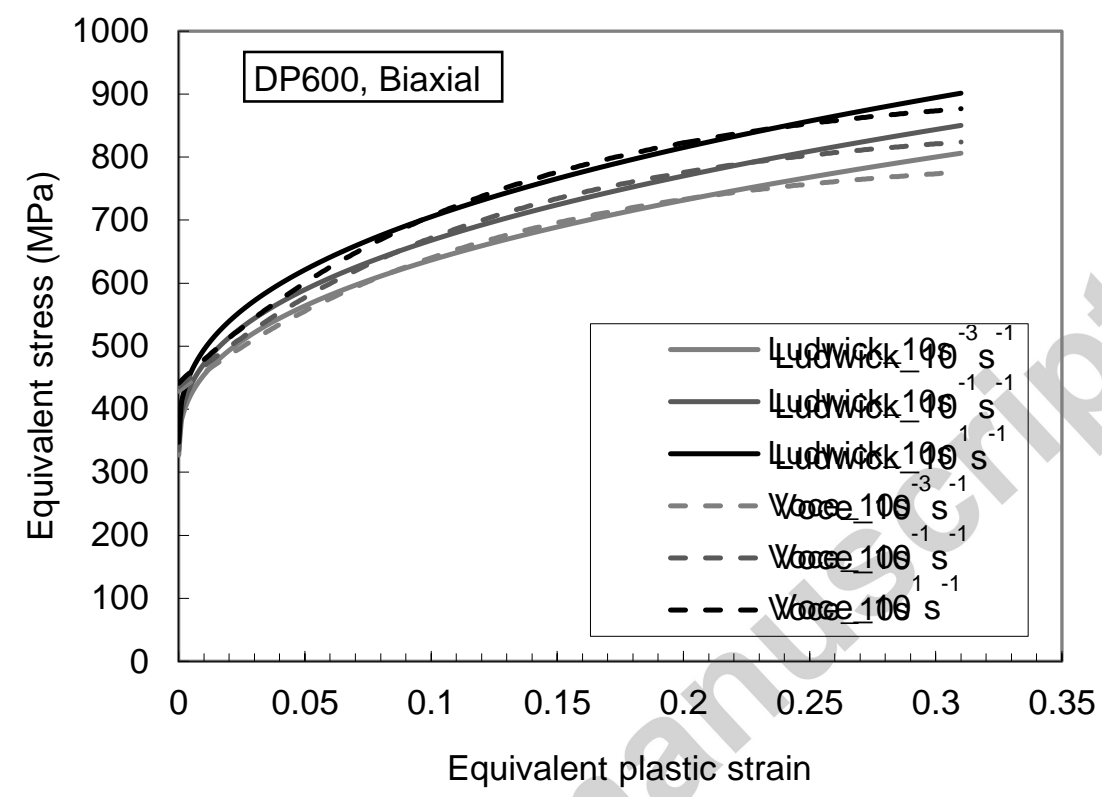

Fig. 14 Strain rate dependent hardening laws identified by biaxial tensile tests

\section{Conclusion}

In this study, the strain rate dependent behaviour of DP600 steel sheets is investigated in an intermediate strain rate range. From classical uniaxial tensile test, it is shown that both initial yield stress and strain hardening are rate-dependent. Based on these experimental observations, two strainrate dependent hardening formulations have been selected: a power-law model described by the wellknown Ludwick's law and a saturation model, based on the classical Voce's formulation. The calibration of these two models from uniaxial tensile tests shows a higher strain-rate dependency of the initial yield stress than the strain hardening. Moreover, the best fit of experimental true stressstrains curves is obtained for the Voce's type law. Nevertheless, results show that the uniaxial tensile test doesn't allow selecting with certainty the formulation of work hardening the most adapted for large strains. 


\section{ACCEPTED MANUSCRIPT}

Dynamic experiments presented in this study validate the capabilities of the servo-hydraulic device used in this study to investigate the rate-dependent behaviour of metallic sheets under biaxial loadings for an intermediate strain rate range. Concerning the geometry of the specimen, it is shown that the cross specimen shape, already validated under quasi-static conditions, can also be used when dynamic biaxial tensile tests are performed. The two work hardening formulations identified in this study give similar results in terms of error function with a strain rate index more important on the strain hardening term than on the initial yield stress.

From these biaxial dynamic experiments, benefits of the proposed methodology are clearly shown by comparing the two identified hardening laws, the "saturation" model and the "power-law" model, which present very different evolutions when identified on uniaxial tensile tests and predict very similar hardening behaviour when calibrated on equi-biaxial tensile tests up to $30 \%$ of equivalent plastic strain. Finally, with such biaxial loadings, the work hardening behaviour can be identified for strain paths corresponding to those encountered in forming processes.

\section{Acknowledgments}

We express our gratitude to ArcelorMittal company for supplying dual phase (DP600) steel sheets characterized in this study.

\section{References}

[1] Y. An, H. Vegter, A novel and simple method for the measurement of the plane strain work hardening, Journal of Materials Processing Technology, 155-156, (2004) 1616-1622.

[2] P. Flores, V. Tuninetti, G. Gilles et al., Accurate stress computation in plane strain tensile tests for the sheet metal using experimental data, Journal of Materials Processing Technology, 210 (2010) 1772-1779.

[3] H. Pijlman, Sheet material characterisation by multi-axial experiments, Doctoral thesis, University of Twente, 2001.

[4] D. Mohr, M. Oswald, A new experimental technique for the multi-axial testing of advanced High strength steel sheets, Experimental Mechanics, 48 (2008) 65-77. 


\section{ACCEPTED MANUSCRIPT}

[5] D.W.A. Rees, Plastic flow in the elliptical bulge test, International Journal of Mechanical Sciences, 37 (1995) 373-389.

[6] T. Kuwabara, Advanced in experiments on metal sheets and tubes in support of constitutive modeling and forming simulations, International Journal of Plasticity, 23 (2007) 382-419.

[7] T. Naka, G. Torikai, R. Hino, and F. Yoshida, The effects of temperature and forming speed on the forming limit diagram for type 5083 aluminium-magnesium alloy sheet, Journal of Materials Processing Technology, 113(1-3):648 - 653, 2001.

[8] S. Kim, H. Huh, H. Bok, and M. Moon, Forming limit diagram of auto-body steel sheets for highspeed sheet metal forming, Journal of Materials Processing Technology, 211(5):851 - 862, 2011. Special Issue: Impulse Forming.

[9] L. Léotoing, D. Guines, I. Zidane, E. Ragneau, Cruciform shape benefits for experimental and numerical evaluation of sheet metal formability, Journal of Materials Processing Technology, 213 (2013) 856-863.

[10] W. Liu, D. Guines, L. Léotoing, E. Ragneau, Identification of sheet metal hardening for large strains with an in-plane biaxial tensile test and a dedicated cross specimen, International Journal of Mechanical Sciences, 101-102 (2015) 387-398.

[11] B. Roebuck, M. Brooks, M. Gee, Load cell ringing in high rate compression tests, Applied Mechanics and Materials, 1-2 (2004) 205-210.

[12] M. Borsuzki, D. Cornette, Y. Kuriyama, A. Uenishi, B. Yan, E. Opbroek, Recommendations for dynamic tensile testing of sheet steels, International Iron and Steel Institute, August (2005).

[13] H. Huh, J. Lim, S. Park, High speed tensile tests of steel sheets for the stress-strain curve at the intermediate strain rate, International Journal of Automotive Technology, 10 (2009) 195-204.

[14] A. Gilat, T. Matrka, A new compression intermediate strain rate testing apparatus, EPJ Web of Conferences 6, 39002 (2010).

[15] R. Othman, P. Guégan, G. Challita, F. Pasco, D. LeBreton, A modified servo-hydraulic machine for testing at intermediate strain rates, International Journal Impact Engineering, 36 (2009) 460-467. [16] P. Wood, C Schley, Strain rate testing of metallic materials and their modeling for use in CAE based automotive crash simulation tools, (2009) ISBN 9781847353740.

[17] S. Diot, D. Guines, A. Gavrus, E. Ragneau, Two-step procedure for identification of metal behaviour from dynamic compression tests, International Journal of Impact Engineering, 34 (2007) 1163-1184.

[18] J. Fitoussi, F. Meraghni, Z. Jendi, G. Hug, D. Baptiste, Experimental methodology for high strain-rates tensile behaviour analysis of polymer matrix composites, Composites Science and Technology, 65 (2005) 2174-2188. 


\section{ACCEPTED MANUSCRIPT}

[19] B. Boyce, M. Dilmore, The dynamic tensile behaviour of tough, ultrahigh-strength steels at strain-rates from $0.0002 s^{-1}$ to $200 s^{-1}$, International Journal of Impact Engineering, 36 (2009) 263271.

[20] X. Xiao, Dynamic tensile testing of plastic materials, Polymer Testing, 27 (2008) 164-178.

[21] V. Grolleau, G. Gary, D. Mohr, Biaxial testing of sheet materials at high strain rates using viscoelastic bars, Experimental Mechanics, 48 (2008) 293-306.

[22] M. Ramezani, Z. Ripin, Combined experimental and numerical analysis of bulge test at high strain rates using split Hopkinson pressure bar apparatus, Journal of Materials Processing Technology, 210 (2010) 1061-1069.

[23] A. Shimamoto, T. Shimomura, J. Nam, The development of servo dynamic biaxial loading device, Key Engineering Materials, 243-244 (2003) 99-104.

[24] I. Zidane, D. Guines, L. Léotoing, E. Ragneau, Development of an in-plane biaxial test for forming limit curve (FLC) characterization of metallic sheets, Measurement Science and Technology, $21(2010) 1-11$.

[25] S. Zhang, L. Léotoing, D. Guines, S. Thuillier, Potential of the cross biaxial test for anisotropy characterization based on heterogeneous strain field, Experimental Mechanics, (2015) 55:817-835.

[26] M.H.H. Meuwissen, C.W.J. Oomens, F.P.T. Baaijens, R. Petterson, J.D. Janssen, Determination of the elasto-plastic properties of aluminium using a mixed numerical-experimental method, Journal of Materials Processing Technology, 75 (1998) 204-11.

[27] S. Belhabib, H. Haddadi, M. Gaspérini, P. Vacher, Heterogeneous tensile test on elastoplastic metallic sheets: comparison between FEM simulations and full-field strain measurements, International Journal of Mechanical Sciences, 50 (2008) 14-21.

[28] J. Kajberg, G. Lindkvist, Characterization of materials subjected to large strains by inverse modelling based on in-plane displacement fields, International Journal of Solids and Structures, 41(13) (2004) 3439-59.

[29] N. Peixinho, A. Pinho, Study of Viscoplasticity Models for the Impact Behavior of HighStrenght Steels, Journal of Computational and Nonlinear Dynamics, Transactions of the ASME, 2 (2007) 114-123.

[30] T. Rahmaan, A. Bardelcik, J. Imbert, C. Butcher, M.J. Worswick, effect of strain rate on flow stress and anisotropy of DP600, TRIP780, and AA5182-O sheet metal alloys, International Journal of Impact Engineering, 88 (2016) 72-90.

[31] J.H. Sung, J.H. Kim, R.H. Wagoner, A plastic constitutive equation incorporating strain, strainrate and temperature, International Journal of Plasticity, 26 (2010) 1746-1771. 


\section{ACCEPTED MANUSCRIPT}

[32] S. Paul, A. Raj, P. Biswas, G. Manikandan, R. Verma, Tensile flow behavior of ultra-low carbon, low carbon and micro alloyed steel sheets for auto application under low to intermediate strain rate, Materials and Design, 57 (2014) 211-217.

[33] H. Yu, Y. Guo, K. Zhang, X. Lai, Constitutive model on the description of plastic behaviour of DP600 steel at strain rate from $10^{-4}$ to $10^{3} \mathrm{~s}^{-1}$, Computational Materials Science, 46 (2009) 36-41.

[34] A.S. Khan, S. Huang, Experimental and theoretical study of mechanical behaviour of 1100 aluminium in the strain rate range $10^{-5} s^{-1}-10^{4} s^{-1}$, International Journal of Plasticity, 8(4) (1992) 397-424.

[35] International Standard ISO16842, Metallic materials - Sheet and strip - Biaxial tensile testing method using a cruciform test piece, 2014.

[36] F. Ozturk, S. Toros, S. Kilic, Effects of anisotropic yield functions on prediction of forming limit diagrams of DP600 advanced high strength steel, ICTP 2014, 19-24 October 2014, Procedia Engineering, 81 (2014) 760-765. 